\title{
Subclinical atrial fibrillation - what is the risk of stroke?
}

\author{
Jiri Plaseka, Milos Taborsky ${ }^{b}$
}

\begin{abstract}
Atrial fibrillation is the most common arrhythmia and as such, it has become a significant public health issue due to its impact on patient morbidity and mortality. The prevalence of atrial fibrillation (AF) almost doubled in the last decade, being currently $2 \%$ in unselected patient populations. Its occurrence varies with age (present in almost $20 \%$ of octogenarians) and concomitant diseases. The most prevalent concomitant diseases are hypertension, diabetes, heart failure, renal failure, and cognitive decline. Cognitive decline or stroke may be actually the first manifestation of undiagnosed atrial fibrillation. In the majority of cases, atrial fibrillation is more of a syndrome than a disease in itself, with a multitude of etiologic factors and mechanisms. The risk of cardioembolic stroke increases with the number of comorbidities and age. The overall age-adjusted risk of stroke in patients with atrial fibrillation is 5 times higher than in the general population. Nowadays, the detection of asymptomatic episodes of atrial fibrillation by cardiac electronic implantable devices (CIED), referred to as device detected or subclinical atrial fibrillation, has opened new frontiers in $\mathrm{AF}$ management. The risk of stroke and subsequent need for anticoagulation treatment in this group of patients with device detected AF is however not clear. Here, we will review the literature to determine the association of subclinical atrial fibrillation with the risk of stroke.
\end{abstract}

Key words: arrhythmia, subclinical atrial fibrilation

Received: October 19, 2018; Accepted: December 19, 2018; Available online: January 10, 2019

https://doi.org/10.5507/bp.2018.083

${ }^{a}$ Deptartment of Cardiovascular Medicine, University Hospital Ostrava, Czech Republic

${ }^{b}$ Department of Internal Medicine I - Cardiology, University Hospital Olomouc, Czech Republic

Corresponding author: Jiri Plasek, e-mail:jiri_plasek@centrum.cz

\section{INTRODUCTION}

Atrial fibrillation (AF) is the most common arrhythmia globally, and due to its impact on morbidity, mortality and quality of life, it has become a significant public health problem. The prevalence of AF is about $2 \%$ in unselected populations, significantly varying with age and $\operatorname{sex}^{1}$. During brief episodes of atrial fibrillation, patients may remain asymptomatic, which renders this arrhythmia challenging to capture. Such subclinical episodes may however represent warning signs for developing detectable forms of $\mathrm{AF}$ and even subclinical/asymptomatic atrial fibrillation (SCAF) may portend significant thromboembolic risk. SCAF is often discovered only after an ischaemic stroke or heart failure or remain silent even after stroke, which leads to inadequate antiaggregant treatment. Current guidelines address none of these issues related to anticoagulation treatment in patients with $\operatorname{SCAF}\left(\right.$ ref. $\left.^{2}\right)$. The risk of stroke and subsequent need for anticoagulation treatment is not clear in the SCAF population, either. There is, however, an expert consensus statement ${ }^{3}$ and a few trials which we will review to question the need for anticoagulation treatment in SCAF, and the threshold for starting the treatment.

\section{SCAF EPIDEMIOLOGY}

The prevalence of AF had increased dramatically over the last three decades, in part due to our greater ability to treat both acute and chronic heart disease and non-cardiac disease, thus improving life expectancy. The population is aging; moreover, with the use of external loop recorders and implantable devices ever increasing, AF is nowadays more likely to be diagnosed than in the past. The prevalence of $\mathrm{AF}$ is $2.3 \%$ in patients older than 40 years and $6 \%$ in patients older than 65 years ${ }^{4}$. The incidence ranges between 0.21 and 0.41 per 1,000 person/years ${ }^{1} .50 \%$ of cases have permanent $\mathrm{AF}$, paroxysmal and persistent are found in $25 \%$ each $^{1}$. The highest prevalence rate, up to $3.2 \%$, was found in developed countries while the lowest in the Asia-Pacific region ${ }^{5}$. In one third of all AF occurrences, some secondary trigger can be observed, such as myocardial infarction, infection or surgery ${ }^{6}$. This should be taken into account, particularly so while interpreting SCAF episodes and their significance. In the TRENDS trial, which included only patients without prior anticoagulation treatment or antiarrhythmic drug use and no history of AF, the incidence of SCAF was $30 \%$ ( ref. $^{7}$ ). Newly detected AF was defined as a device detected atrial high rate episode lasting more than 5 minutes. In another landmark trial (ASSERT) ( ref. $\left.^{8}\right)$, SCAF was defined as an atrial high rate episode of $\geq 190 \mathrm{bpm}$ lasting more than 6 min. Subclinical atrial fibrillations detected by implantable devices occurred in $10.1 \%$ of cases in the ASSERT trial ${ }^{8}$.

Clinically silent $\mathrm{AF}$ is often revealed after pacemaker implantation. AF occurs more often in patients with a sick sinus syndrome (68\%) than with an AV blockade (37\%) (ref. ${ }^{9}$ ). The median time to the first occurrence was 21.2 
days after pacemaker implantion ${ }^{9}$. In the MOST trial, the pacemakers were programmed to log on an episode as an atrial high-rate episode (AHRE) when the atrial rate was $\geq 220 / \mathrm{min}$ and lasting for ten consecutive beats, however only AHREs lasting more than 5 min were included in the final analysis ${ }^{10}$. In $51.3 \%$ patients, at least one AHRE episode was observed during the follow-up (median duration follow up 27 months), although at least $60 \%$ of patients had a history of unspecified supraventricular tachycardia ${ }^{10}$. In the BEATS trial, the atrial tachycardia detection was programmed to 8 atrial cycles at 170/min. Based on pacemaker counter data, atrial tachycardias (AT) were recorded during follow-up at least once in $85 \%$ of patients with sinus node disease and in $83 \%$ patients with other pacing indications, mostly AV blockades ${ }^{11}$. Of the patients with sinus node disease and device-detected AT (DDAT), the episodes were confirmed by 12 lead ECG/Holter recordings in $18 \%$ of patients; in patients with other pacing indications, it was only $10 \%$ of patients. The total number of SCAF observed in the BEATS trial was $67 \%$ in sinus node disease patients and $73 \%$ in the other pacing indications group ${ }^{11}$. In the BEATS trial, the use of anticoagulation or antiarrhythmic drugs was not an exclusion criterion. In another monocentric retrospective analysis (445 patients), AF was detected in $55.3 \%$ of patients including patients both with $(65.8 \%)$ and without $(51.8 \%)$ the history of clinical arrhythmia ${ }^{12}$.

\section{SCAF terminology}

At present, there are generally two European heart rhythm association (EHRA) consensus documents ${ }^{3,13}$ dealing with subclinical forms of atrial fibrillation. We find it useful to delineate all types of AF/AT episodes. Although EHRA issued both documents, there are differences in definitions of AHRE rate (180 vs. 190/min), length of subclinical AF ( 5 vs. $6 \mathrm{~min}$ ) and excessive supraventricular ectopic activity (ESVEA), which is defined only in the document by Gorenek et al. ${ }^{3}$, see Table 1 for details.

\section{HOW TO DETECT SCAF}

The detection rate of subclinical AF depends heavily on the length of ECG monitoring and amount of classical risk factors for AF. There were two principal landmarks in the search for subclinical forms of atrial fibrillation. The first was the development and then refining of device detection algorithms. The second was the need for detection of AF in patients with cryptogenic stroke (or, as it is termed now, embolic stroke of undetermined source, ESUS) and causal connection of these diseases ${ }^{14}$. In 2014, two important trials comparing standard 24-h ECG Holter with extended ECG monitoring in the cryptogenic stroke patients were published ${ }^{15,16}$. The EMBRACE trial compared a 24-h ECG Holter monitoring vs. a 30-day external loop recorder (ELR) in 572 cryptogenic stroke patients of 55 years and older less than six months after stroke. The result was stunning, AF was detected in $16.1 \%$ of ELR patients while only in $3.2 \%$ patients in the standard $\operatorname{arm}^{15}$. The CRYSTAL-AF trial compared the standard 24-h ECG Holter monitoring against 6-month implantable loop recorder (ILR) in 441 patients over 40 years of age, less than three months after a cryptogenic stroke. Not surprisingly, AF was detected in $12.4 \%$ in the active arm (ILR) and only $2 \%$ in the standard arm ${ }^{16}$. Lower detection rate comparing ILR vs. ELR might be explained by lower risk patients (younger) in the CRYSTAL-AF trial, which also explains the lower AF capture in the standard $\operatorname{arm}\left(2 \%\right.$ vs. $3 \%$ in the EMBRACE trial) (ref. $\left.{ }^{15,16}\right)$. These results led to the recommendation in stroke guidelines for 30 days ECG monitoring after stroke or transient ischaemic attack with no apparent cause ${ }^{17}$. The development of the focus aimed at subclinical atrial fibrilation is also traceable by Pubmed search, from which the effect of fundamental SCAF publications (such as AIDA (ref. ${ }^{18}$ ), MOST (ref. ${ }^{10}$ ), ASSERT (ref. ${ }^{8}$ ) or TRENDS (ref. ${ }^{7}$ ) trials) on the number of papers devoted to SCAF are apparent, see Fig. 1. In patients with cardiac implantable devices, the average SCAF detection rate is $30 \%$; the peaks of $60 \%$ rates were reported in the early trials where the inclusion

Table 1. EHRA consensus documents, subclinical atrial fibrillation terminology $\mathrm{y}^{2,3}$.

\begin{tabular}{|c|c|c|}
\hline Definition & $\begin{array}{l}\text { EHRA consensus document: Screening for atrial } \\
\text { fibrillation }^{2}\end{array}$ & $\begin{array}{l}\text { EHRA consensus document: Device detected } \\
\text { subclinical atrial tachycardias }{ }^{3}\end{array}$ \\
\hline $\begin{array}{l}\text { SCAF (Subcinical } \\
\text { atrial fibrillation) }\end{array}$ & $\begin{array}{l}\text { Episodes of AF/AT with duration between } 5 \text { min to } \\
24 \text { h detected in patients without clinical history or } \\
\text { symptoms of AF }\end{array}$ & $\begin{array}{l}\text { AHREs }(>6 \text { min and }<24 \mathrm{~h} \text { ) with lack of symp- } \\
\text { toms in patients with CIEDs; detected with conti- } \\
\text { nous ECG monitoring (intracardiac) and without } \\
\text { prior diagnosis of AF (ECG or holter monitoring) }\end{array}$ \\
\hline $\begin{array}{l}\text { Asymptomatic or } \\
\text { clinically silent AF }\end{array}$ & $\begin{array}{l}\text { Episodes of at least of } 30 \mathrm{~s} \text { ECG documented } \\
\text { absolutely irregular RR intervals with no discern- } \\
\text { able distinct P waves in the absence of symptoms } \\
\text { typically associated with AF }\end{array}$ & $\begin{array}{l}\text { Documented AF in the absence of any symptoms } \\
\text { or prior diagnosis } \\
\text { Often presenting with a complication related to } \mathrm{AF}\end{array}$ \\
\hline $\begin{array}{l}\text { AHRE (Atrial high- } \\
\text { rate episodes) }\end{array}$ & $\begin{array}{l}\text { Episodes of at least } 5 \text { min and of AT/AF with } \\
\text { atrial rate }>180 / \text { min detected by continous moni- } \\
\text { toring by CIEDs }\end{array}$ & $\begin{array}{l}\text { Atrial tachyarrhythmia episodes of with rate }>190 \text { / } \\
\text { min detected by CIEDs }\end{array}$ \\
\hline $\begin{array}{l}\text { ESVEA (Excesive } \\
\text { supraventricular } \\
\text { ectopic activity) }\end{array}$ & - & $\begin{array}{l}30 \mathrm{PSC} / \mathrm{h}(729 / 24 \mathrm{~h}) \text { or episode of PSC runs } \geq 20 \\
\text { beats }\end{array}$ \\
\hline
\end{tabular}


Pubmed: subclinical+atrial+fibrillation

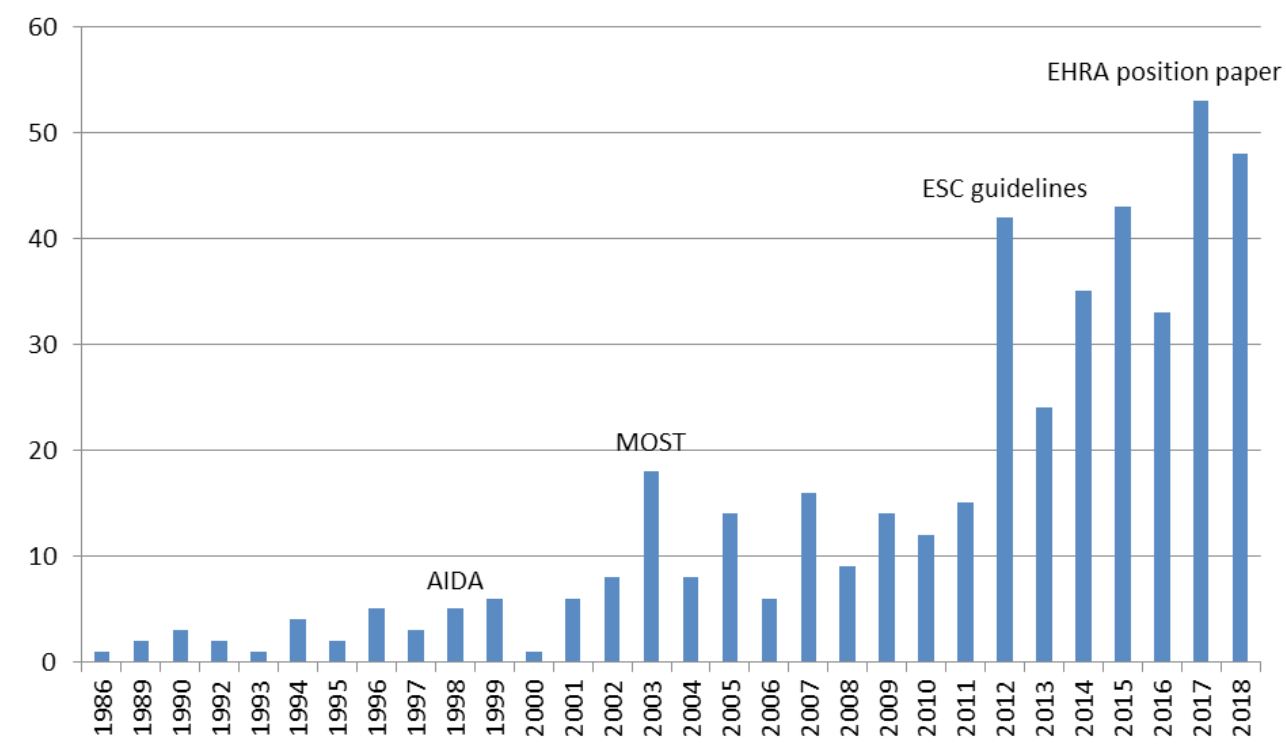

Fig. 1. Evolution of the number of publications related to SCAF, with indication of the milestone studies of subclinical atrial fibrillation as documented by Medline database; best match search keywords in the title.

\section{Pubmed: subclinical+atrial+fibrillation+stroke}

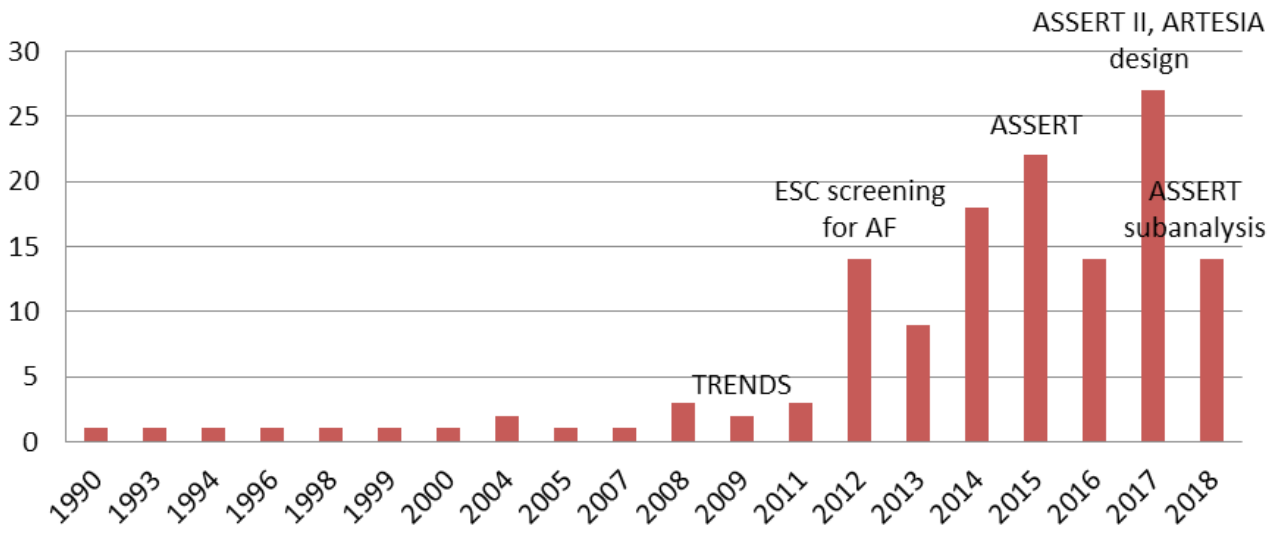

Fig. 2. Evolution of the number of publications with indication of the milestone studies of subclinical atrial fibrillation and its association with stroke as documented by Medline database; best match search - keywords in the title.

criteria according to AF history were not so strict ${ }^{3}$. With the exception of the ASSERT trial ${ }^{8}$, data on the percentage of previous paroxysmal AF were not provided.

\section{Detection algorithms reliability/remote monitoring}

Cardiac implantable devices (CIEDs) provide various rhythm monitoring features depending on the type and year of issue. The early ones were able only to detect predefined AHREs, while nowadays, most devices can record full disclosure ECG of each episode, AF burden, and ventricular rate. With the number of CIEDs recipients growing exponentially, we have to find effective ways to make use of their extensive diagnostic power. A unique opportunity for SCAF detection is remote monitoring of CIEDs. At least two non-randomized trials evaluated the effectiveness and accuracy of AF detection in home monitoring systems ${ }^{19,20}$. Both studies reported optimization of medical treatment associated with earlier detection of SCAF. No data loss was observed in either of the studies. Three more randomized trials (TRUST, CONNECT, IN-TIME) (ref. ${ }^{21-23}$ ) confirmed the efficacy, safety and reduction of time to the clinical decision in remotely monitored patients; in these trials, however, AF detection was not the primary end-point.

The AF detection algorithms are in most cases correct, there are however several limitations. One of the issues is associated with oversensing of far-field $\mathrm{R}$ waves on the atrial channel, which may occur both during ventricular sensing or ventricular pacing. This false positive AF detection may occur in $2-20 \%$ depending on the tip to 
ring electrode spacing and position of the atrial lead ${ }^{24,25}$. The other issue of CIEDs is atrial undersensing causing underdetection of AF and erroneous logging of longlasting episodes as multiple short episodes. The positive predictive value for SCAF detection has been shown to be $91 \%$ for Biotronik devices ${ }^{26}$ and $95.3 \%$ for Medtronic devices $^{27}$. For St. Jude Medical devices, more specific data are available: for AF episodes lasting $>6 \mathrm{~h}$, the positive predictive value has been shown to be $96.7 \%$ while for AF episodes lasting between 6 min and 6 hours, the positive predictive value has been shown to be only $82.7 \%$ (ref. ${ }^{28}$ ).

\section{Controversies}

A growing number of CIEDs and thus detected SCAF spurred interest in the effective management of this patient group, first of all regarding the initiation of anticoagulation treatment. We have to ask the right questions, however. What is the key parameter for starting the anticoagulation treatment? The length of the AHRE episode? The frequency of the particular AHRE? Clustering of the episodes? How reliable is the detection algorithm of each device and do we have to wait for another ECG confirmation of SCAF episode? Are thus device-detected episodes somehow different from AF episodes detected by ECG Holter or loop recorder? What are those episodes themselves - are they indicators of risk or mere risk factors? Given the results of TRENDS and ASSERT trials, are we still convinced that the temporal relationship between AF and stroke even exists?

\section{What is the stroke risk?}

From the Framingham study, we know that the AFrelated thromboembolic risk rises linearly from the 6th to 9 th decade from 1.5 to $24 \%$, respectively ${ }^{29}$. Approximately $17 \%$ of strokes are attributable to documented AF. Moreover, AF-related strokes are associated with a higher mortality rate ${ }^{29}$. We however do not know whether it holds true also for subclinical atrial fibrillation. Major trials assessing the risk of thromboembolic events are summarized in Table 2. We may state that in all of these trials, the risk of a thromboembolic event is increased when AHRE is detected. An episode of at least $5 \mathrm{~min}$ of device-detected AF was associated with an increased risk of thromboembolic event, the risk was further increasing with the duration of the AHRE (ref. ${ }^{3,7,8,10,26}$ ). The threshold is not clear as the cut-off values for minimal AF burden were either chosen arbitrarily or represented by median values. We have insufficient data to confirm that the frequency during AHRE plays any role in the stroke risk ${ }^{3,7,8,10,26}$. Mahajan et al. reported in a meta-analysis of 7 trials (15,353 patients) a 2.4-fold increase of the stroke risk in SCAF patients (95\% CI 1.8-3.3, $P<0.001$, I $2=0 \%, P=0.69$ for heterogeneity) irrespective of AHRE duration ${ }^{30}$. The absolute annual stroke risk in SCAF patients was 1.89 (95\% CI 1.02-3.52), and 0.93 (95\% CI 0.58-1.49) in patients without SCAF; including only patients with a median $\mathrm{CHADS}_{2}$ score of 2.1, the absolute risk increased to 2.76 (95\% CI 1.46-5.23) (ref. $\left.{ }^{30}\right)$. In five studies including altogether 8551 patients, 181 strokes were observed, of which only 98 strokes occurred in patients who had an AF episode during follow-up ${ }^{30}$. In the TRENDS and ASSERT trials, AF episodes were detected in a period of 30 days before stroke only in 55\% and $22 \%$ of patients ${ }^{7,8}$. A TRENDS substudy on the temporal proximity of AF episodes to thromboembolic events however demonstrated a higher AF burden in patients with AHRE $<30$ days before stroke ${ }^{31}$.

Similarly, the ASSERT trial showed in patients with detected SCAF within 30 days of stroke longer AHRE episodes; besides, SCAF longer than $24 \mathrm{~h}$ was associated with significantly increased risk of stroke, see Table 3 $\left(\right.$ ref. $\left.^{32}\right)$. While the risk of stroke is increased even in shorter AHREs, the guidelines ${ }^{2}$ recommend starting anticoagulation in case of AHREs lasting 5-6 min with $>180 / \mathrm{min}$ in

Table 2. SCAF trials characteristics according to AHRE frequency, follow-up and thromboembolic risk.

\begin{tabular}{lccccll}
\hline STUDY & YEAR & \multicolumn{1}{c}{$\mathrm{n}$} & Follow-up & Rate/bpm & Duration & HR for TE event \\
\hline MOST & 2003 & 312 & $27 \mathrm{~m}$ & $>220$ & $5 \mathrm{~min}$ & 6.7 \\
AT 500 registry & 2005 & 725 & $22 \mathrm{~m}$ & $>274$ & $24 \mathrm{~h}$ & 3.1 \\
TRENDS & 2009 & 2486 & $1.4 \mathrm{yr}$ & $>175$ & $5.5 \mathrm{~h}$ & 2.2 \\
Home monitoring/CRT & 2012 & 560 & $370 \mathrm{days}$ & $>180$ & $3.8 \mathrm{~h}$ & 9.4 \\
ASSERT & 2012 & 2580 & $2.5 \mathrm{yr}$ & $>190$ & $>6 \mathrm{~min}$ & 2.5 \\
SOS-AF & 2014 & 10,016 & $2 \mathrm{yr}$ & $>175$ & $1 \mathrm{~h}$ & 2.11 \\
RATE & 2016 & 5379 & $22.9 \mathrm{~m}$ & - & Short AHRE - 1 EGM & $1.75 /$ long AHRE \\
& & & & & Long AHRE - blond 1 EGM & 3.24 for AHRE $>24 \mathrm{~h}$ \\
\hline
\end{tabular}

Table 3. Risk of stroke in ASSERT trial according to AHRE duration ${ }^{32}$.

\begin{tabular}{lcccc}
\hline AHRE & Event rate \%/year & aHR $(1$ year $)$ & $95 \%$ CI & $P$ \\
\hline no SCAF $(<6 \mathrm{~min})$ & 0.54 & 1 & - & - \\
$>6 \mathrm{~min}-6 \mathrm{~h}$ & 1.14 & 1.75 & $0.69-4.44$ & 0.24 \\
$>6-24 \mathrm{~h}$ & 0.95 & 1.85 & $0.43-8.01$ & 0.41 \\
$>24 \mathrm{~h}$ & 3.08 & 5.37 & $2.08-13.87$ & 0.001 \\
\hline
\end{tabular}




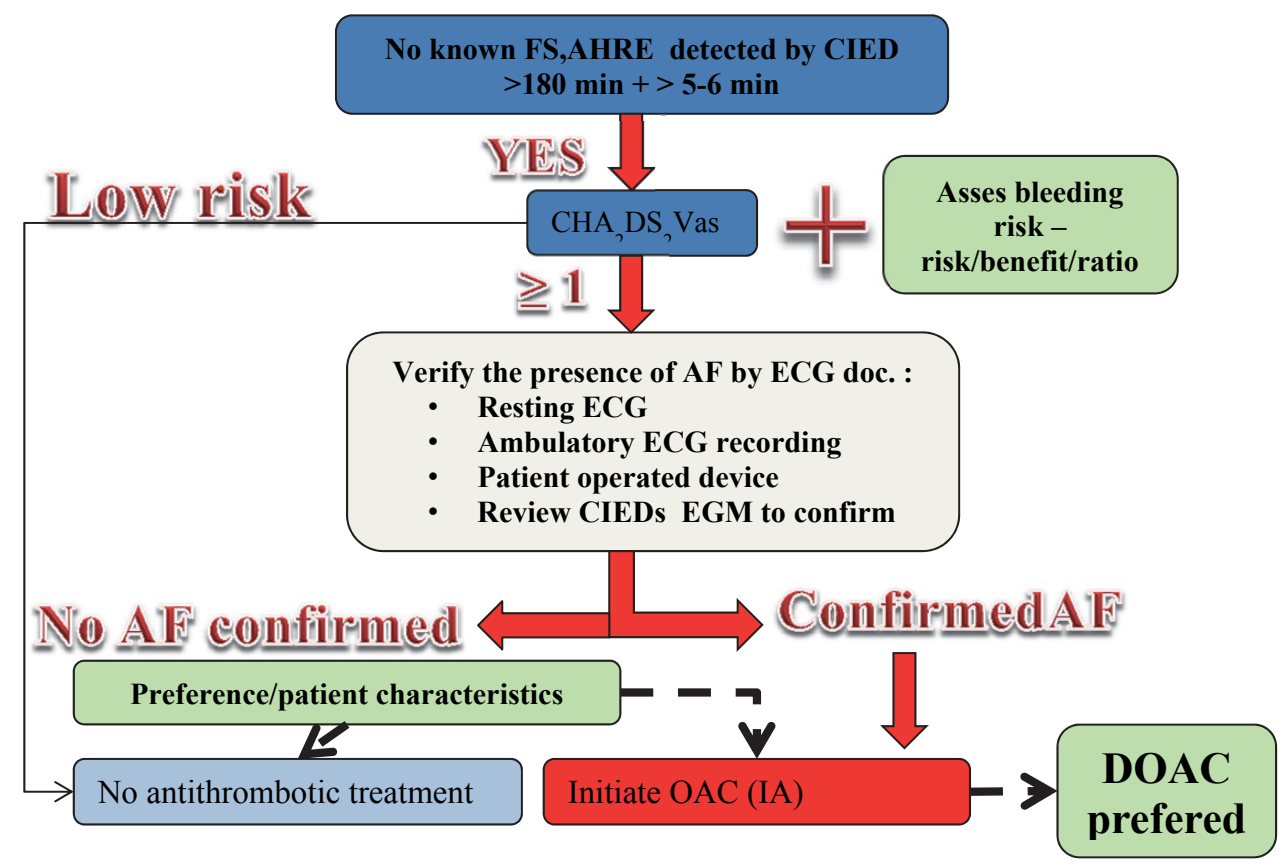

Fig. 3. Algorithm for anticoagulation initiation in patients with AHRE as a surrogate for AF detection. Modified from Kirchhof P. et al. Eur J Cardiothorac Surg 2016;50(5):e1-e88.

$\mathrm{CHA}_{2} \mathrm{DS}_{2}$ Vasc score $\geq 1$ - for more details, see the algorithm in the Fig. 3. The EHRA position paper ${ }^{3}$ defines the threshold as follows: for patients with $\mathrm{CHA}_{2} \mathrm{DS}_{2}$ Vasc $\geq 2$ in males and $\geq 3$ in females, oral anticoagulation (OAC) is recommended for $\mathrm{AF}$ burden $>5.5 \mathrm{~h} /$ day. The lower duration may merit $\mathrm{OAC}$ if multiple risk factors are present ${ }^{3}$. There were also attempts to administer the OAC treatment only during device-detected arrhythmia. The IMPACT trial was prematurely stopped for futility, the strategy of early initiation and interruption of anticoagulation based on remotely detected AT did neither prevent thromboembolism events nor bleeding ${ }^{33}$. The TACTIC trial ${ }^{34}$ tested intermittent anticoagulation in patients with continuous AF burden monitoring in low to moderate risk patients with rare episodes of AF. Pacemaker (PM)/Implantable cardioverter-defibrillator (ICD)-guided DOAC administration has been shown to be feasible and reduced the use of anticoagulation therapy by $75 \%$. The trial however did not have sufficient statistical power to show a significant difference in bleeding and thromboembolic episodes. Intermittent $\mathrm{AF}$ burden-related anticoagulation might be promising in low to moderate risk patients but in high-risk patient AF might be only one of the causes of TE risk. Atrial cardiomyopathy might be an isolated risk factor for thromboembolic events irrespective of atrial fibrillation ${ }^{35}$. Two other randomized controlled trials (ARTESIA, NCT 01938248; NOAH-AFNET 6, NCT 02618577) are testing the potential of AHRE-guided anticoagulation therapy. In ARTESIA trial ${ }^{36}$, inclusion criterion is at least one episode of AHRE > 6 min with an atrial rate > 175/min while a single episode lasting $>24 \mathrm{~h}$ is an exclusion criterion; the primary end-point is stroke and systemic embolism and the patients are randomized to groups administered either apixaban ( $5 \mathrm{mg}$ bi-daily) or aspirin $81 \mathrm{mg} / \mathrm{d}$.
The NOAH AFNET 6 trial tests whether oral anticoagulation with edoxaban is superior in prevention of stroke or cardiovascular death compared with aspirin or no antithrombotic therapy based on evidence-based indications ${ }^{37}$.

\section{CONCLUSION}

Subclinical atrial fibrillation is quite common, especially in patients with cardiac implantable devices where it occurs in $30 \%$ of patients. SCAF duration $\geq 24 \mathrm{~h}$ is associated with significant risk of thromboembolic events. The minimum threshold to start anticoagulation is unknown and the recommendations of ESC/EHRA are contradictory. There is no good clinical evidence that anticoagulation treatment in AHRE/SCAF is effective. Two trials are ongoing. At present, an individual approach accounting for thromboembolic risk factors and AHRE duration has to be adopted.

\section{Search strategy and selection criteria}

Our research strategy was aimed at evaluating studies on the link between subclinical atrial fibrillation and the risk of stroke. Scientific articles from 1986 to 2018 were searched using the PubMed and Web of Science databases. All searches were up to date as of October 2018. The search terms used included "subclinical atrial fibrillation," "stroke risk," "device detected atrial fibrillation," "SCAF," "AHRE." Only English language papers were reviewed.

Acknowledgement: Institutional grant number 2 RVOFNOs/2015, Ministry of Health.

Author contributions: JP: manuscript writing, literature search; MT: critical review of the manuscript. 
Conflict of interest statement: The authors state that there is no conflict of interest regarding the publication of this article.

\section{REFERENCES}

1. Zoni-Berisso M, Lercari F, Carazza T, Domenicucci S. Epidemiology of atrial fibrillation: European perspective. Clin Epidemiol 2014;6:21320. doi: $10.2147 /$ CLEP.S47385

2. Kirchof $P$, Benussi S, Kotecha D, Ahlsson A, Atar D, Casadei B, Castella M, Diener HC, Heidbuchel H, Hendriks J, Hindricks G, Manolis AS, Oldgren J, Popescu BA, Schotten U, Van Putte B, Vardas P, Agewall S, Camm J, Baron Esquivias G, Budts W, Carerj S, Casselman F, Coca A, De Caterina R, Deftereos S, Dobrev D, Ferro JM, Filippatos G, Fitzsimons D, Gorenek B, Guenoun M, Hohnloser SH, Kolh P, Lip GY, Manolis A, McMurray J, Ponikowski P, Rosenhek R, Ruschitzka F, Savelieva I, Sharma S, Suwalski P, Tamargo JL, Taylor CJ, Van Gelder IC, Voors AA, Windecker S, Zamorano JL, Zeppenfeld K. 2016 ESCguidelines for management of atrial fibrillation developed in collaboration with EACTS. Eur J Cardiothorac Surg 2016;50(5):e1-e88.

3. Gorenek B Chair, Bax J, Boriani G, Chen SA, Dagres N, Glotzer TV, Healey JS, Israel CW, Kudaiberdieva G, Levin LÅ, Lip GYH, Martin D, Okumura K Svendsen JH, Tse HF, Botto GL Co-Chair; ESC Scientific Document Group. Device-detected subclinical atrial tachyarrhythmias: definition, implications and management-an European Heart Rhythm Association (EHRA) consensus document, endorsed by Heart Rhythm Society (HRS), Asia Pacific Heart Rhythm Society (APHRS) and Sociedad Latinoamericana de Estimulación Cardíaca y Electrofisiología (SOLEACE). Europace 2017;19(9):1556-78. doi: 10.1093/europace/eux163

4. Go AS, Hylek EM, Phillips KA, Chang Y, Henault LE, Selby JV, Singer DE.Prevalence of diagnosed atrial fibrillation in adults: National implications for rhythm management and stroke prevention: The AnTicoagulation and Risk Factors in AtrialFibrillation (ATRIA) Study. JAMA 2001;285:2370-5.

5. Chugh SS, Havmoeller R, Narayanan K, Singh D, Rienstra M, Benjamin EJ, Gillum RF, Kim YH, McAnulty JH Jr, Zheng ZJ, Forouzanfar MH, Naghavi M, Mensah GA, Ezzati M, Murray CJ. Worldwide epidemiology of atrial fibrillation: a Global Burden of Disease 2010 Study. Circulation 2014;129:837-47.

6. Dilaveris PE, Kennedy HL. Silent atrial fibrillation: epidemiology, diagnosis, and clinical impact. Clin Cardiol 2017;40(6):413-8.

7. Ziegler PD, Glotzer TV, Daoud EG, Singer DE, Ezekowitz MD, Hoyt RH, Koehler JL, Coles J Jr, Wyse DG. Detection of previously undiagnosed atrial fibrillation in patients with strokerisk factors and usefulness of continuous monitoring in primary stroke prevention. Am J Cardiol 2012;110:1309-14.

8. Healey JS, Connolly SJ, Gold MR, Israel CW, Van Gelder IC, Capucci A, ASSERT Investigators. Subclinical atrial fibrillation and the risk of stroke. N Engl J Med 2012;366:120-9.

9. Gillis AM, Morck M. Atrial fibrillation after DDDR pacemaker implantation. J Cardiovasc Electrophysiol 2002;13:542-7.

10. Glotzer TV, Hellkamp AS, Zimmerman J, Sweeney MO, Yee R, Marinchak R, MOST Investigators. Atrial high rate episodes detected by pacemaker diagnostics predict death and stroke: report of the Atrial Diagnostics AncillaryStudy of the MOde Selection Trial (MOST). Circulation 2003;107:1614-9.

11. Israel CW, Neubauer H, Olbrich HG, Hartung W, Treusch S, Hohnloser $\mathrm{SH}$.Incidence of atrial tachyarrhythmias in pacemaker patients: results from theBalanced Evaluation of Atrial Tachyarrhythmias in Stimulated patients (BEATS). Study. Pacing Clin Electrophysiol 2006;29:582-8.

12. Healey JS, Martin JL, Duncan A, Connolly SJ, Ha AH, Morillo CA, Nair GM, Eikelboom J, Divakaramenon S, Dokainish H. Pacemakerdetected atrial fibrillation in patients with pacemakers: prevalence, predictors, and current use of oral anticoagulation. Can J Cardiol 2013;29:224-8

13. Mairesse GH, Moran P, Van Gelder IC, Elsner C, Rosenqvist M, Mant J, Banerjee A, Gorenek B, Brachmann J, Varma N, Glotz de Lima G, Kalman J, Claes N, Lobban T, Lane D, Lip GYH, Boriani G; ESC Scientific Document Group. Screening for atrial fibrillation: a European Heart
Rhythm Association (EHRA) consensus document endorsed by the Heart Rhythm Society (HRS), Asia Pacific Heart Rhythm Society (APHRS), and Sociedad Latinoamericana de Estimulación Cardíaca y Electrofisiología (SOLAECE). Europace 2017;19(10):1589-1623. doi: 10.1093/europace/eux177

14. Hart RG, Diener HC, Coutts SB, Easton JD, Granger CB, O'Donnell MJ, Sacco RL, Connolly SJ; Cryptogenic Stroke/ESUS International Working Group. Embolic strokes of undetermined source: the case for a new clinical construct. Lancet Neurol 2014;13(4):429-38. doi: 10.1016/S1474-4422(13)70310-7

15. Gladstone DJ, Spring $M$, Dorian $P$, Panzov V, Thorpe KE, Hall J, Vaid H, O'Donnell M, Laupacis A, Côté R, Sharma M, Blakely JA, Shuaib A, Hachinski V, Coutts SB, Sahlas DJ, Teal P, Yip S, Spence JD, Buck B, Verreault S, Casaubon LK, Penn A, Selchen D, Jin A, Howse D, Mehdiratta M, Boyle K, Aviv R, Kapral MK, Mamdani M; EMBRACE Investigators and Coordinators. Atrial fibrillation in patients with cryptogenic stroke. N Engl J Med 2014;370(26):2467-77. doi: 10.1056/NEJMoa1311376

16. Sanna T, Diener HC, Passman RS, Di Lazzaro V, Bernstein RA, Morillo CA, Rymer MM, Thijs V, Rogers T, Beckers F, Lindborg K, Brachmann J; CRYSTAL AF Investigators. Cryptogenic stroke and underlying atrial fibrillation. N Engl J Med 2014;370(26):2478-86. doi: 10.1056/ NEJMoa1313600

17. Kernan WN, Ovbiagele B, Black HR, Bravata DM, Chimowitz MI, Ezekowitz MD, Fang MC, Fisher M, Furie KL, Heck DV, Johnston SC, Kasner SE, Kittner SJ, Mitchell PH, Rich MW, Richardson D, Schwamm LH, Wilson JA; American Heart Association Stroke Council, Council on Cardiovascular and Stroke Nursing, Council on Clinical Cardiology, and Council on Peripheral Vascular Disease. Guidelines for the prevention of stroke in patients with stroke and transient ischemic attack: a guideline for healthcare professionals from the American Heart Association/American Stroke Association. Stroke 2014;45(7):2160-236. doi: 10.1161/STR.0000000000000024

18. Defaye P, Dournaux F, Mouton E. Prevalence of supraventricular arrhythmias from the automated analysis of data stored in the DDD pacemakers of 617 patients: the AIDA study. The AIDA Multicenter Study Group. Automatic Interpretation for Diagnosis Assistance. Pacing Clin Electrophysiol 1998;21(1 Pt 2):250-5.

19. Varma N, Stambler B, Chung S. Detection of atrial fibrillation by implanted devices with wireless data transmission capability. Pacing Clin Electrophysiol 2005;28:S133-6.

20. Ricci RP, Morichelli L, Santini M. Remote control of implanted devices through Home Monitoring technology improves detection and clinical management of atrial fibrillation. Europace 2009;11:54-61.

21. Varma N, Epstein A, Irimpen A, Schweikert R, Shah J, Love CJ. Trust trial Investigators. Efficacy and safety of automatic remote monitoring for ICD Follow-Up: the TRUST trial. Circulation 2010;122:325-32.

22. Crossley G, Boyle A, Vitense H, Chang Y, Mead RH. The clinical evaluation ofremote notification to reduce time to clinical decision (CONNECT) trial: thevalue of wireless remote monitoring with automatic clinician alerts. J Am CollCardiol 2011;57:1181-9.

23. Hindricks $G$, Taborsky M, Glikson M, Heinrich $U$, Schumacher B, Katz A, Brachmann J, Lewalter T, Goette A, Block M, Kautzner J, Sack S, Husser D, Piorkowski C, Søgaard P; IN-TIME study group*. Implantbased multiparameter telemonitoring of patients with heart failure (IN-TIME): a randomized controlled trial. Lancet 2014;384(9943):58390. doi: 10.1016/S0140-6736(14)61176-4

24. Inama G, Santini M, Padeletti L, Boriani G, Botto G, Capucci A, Gulizia M, Ricci R, Rizzon P, Ferri F, Miraglia F, Raneri R, Grammatico A. Farfield $R$ wave oversensing in dual chamber pacemakers designed for atrial arrhythmia management: effect of pacing site and lead tip to ring distance. Pacing Clin Electrophysiol 2004;27(9):1221-30.

25. Minamiguchi $H$, Abe $H$, Kohno R, Oginosawa $Y$, Tamura M, Takeuchi M, Nagatomo T, Otsuji Y. Incidence and characteristics of far-field R-wave sensing in low right atrial septum pacing. Circ J 2012;76(3):598-606.

26. Martin DT, Bersohn MM, Waldo AL, Wathen MS, Choucair WK, Lip GY, Ip J, Holcomb R, Akar JG, Halperin JL; IMPACT Investigators. Randomized trial of atrial arrhythmia monitoring to guide anticoagulation in patients with implanted defibrilátor and cardiac resynchronization devices. Eur Heart J 2015;36:1660-8.

27. Purerfellner H, Gillis AM, Holbrook R, Hettrick DA. Accuracy of atrial tachyarrhythmia detection in implantable devices with arrhythmia therapies. Pacing Clin Electrophysiol 2004;27:983-92. 
28. Kaufman ES, Israel CW, Nair GM, Armaganijan L, Divakaramenon S, Mairesse GH, Brandes A, Crystal E, Costantini O, Sandhu RK, Parkash R, Connolly SJ, Hohnloser SH, Healey JS; ASSERT Steering Committee and Investigators. Positive predictive value of device-detected atrial high-rate episodes at different rates and durations: an analysis from ASSERT. Heart Rhythm 2012;9:1241-6.

29. Wolf PA, Abbott RD, Kannel WB. Atrial fibrillation as an independent risk factor for stroke: the Framingham Study. Stroke 1991;22:983-8.

30. Mahajan R, Perera T, Elliott AD, Twomey DJ, Kumar S, Munwar DA, Khokhar KB, Thiyagarajah A, Middeldorp ME, Nalliah CJ, Hendriks JML, Kalman JM, Lau DH, Sanders P. Subclinical device-detected atrial fibrillation and stroke risk: a systematic review and meta-analysis. Eur Heart J 2018;39(16):1407-15. doi: 10.1093/eurheartj/ehx731

31. Daoud EG, Glotzer TV, Wyse DG, Ezekowitz MD, Hilker C, Koehler J, Ziegler PD. Temporal relationship of atrial tachyarrhythmias, cerebrovascular events, and systemic emboli based on stored device data: a subgroup analysis of TRENDS. Heart Rhythm 2011;8:1416-23.

32. Van Gelder IC, Healey JS, Crijns HJGM, Wang J, Hohnloser SH, Gold MR, Capucci A, Lau CP, Morillo CA, Hobbelt AH, Rienstra M, Connolly SJ. Duration of device-detected subclinical atrial fibrillation and occurrence of stroke in ASSERT. Eur Heart J 20171;38(17):1339-44. doi: 10.1093/eurheartj/ehx042

33. Martin DT, Bersohn MM, Waldo AL, Wathen MS, Choucair WK, Lip GY, Ip J, Holcomb R, Akar JG, Halperin JL, IMPACT Investigators. Randomized trial of atrial arrhythmia monitoring to guide antico- agulation in patients with implanted defibrillator and cardiac resynchronization devices. Eur Heart J 2015;36(26):1660-8. doi: 10.1093/ eurheartj/ehv115

34. Waks JW, Passman RS, Matos J, Reynolds M, Thosani A, Mela T, Pederson D, Glotzer TV, Zimetbaum P. Intermittent anticoagulation guided by continuous atrial fibrillation burden monitoring using dual-chamber pacemakers and implantable cardioverter-defibrillators: Results from the Tailored Anticoagulation for Non-Continuous Atrial Fibrillation (TACTIC-AF) pilot study. Heart Rhythm 2018;15(11):16017. doi: 10.1016/j.hrthm.2018.06.027

35. Guichard JB, Nattel S. Atrial Cardiomyopathy: A Useful Notion in Cardiac Disease Management or a Passing Fad? J Am Coll Cardiol 2017;70(6):756-65. doi: 10.1016/j.jacc.2017.06.033

36. Lopes RD, Alings $\mathrm{M}$, Connolly SJ, Beresh $\mathrm{H}^{3}$, Granger $\mathrm{CB}$, Mazuecos JB, Boriani G, Nielsen JC, Conen D, Hohnloser SH, Mairesse GH, Mabo P, Camm AJ, Healey JS. Rationale and design of the Apixaban for the Reduction of Thrombo-Embolism in Patients With DeviceDetected Sub-Clinical Atrial Fibrillation (ARTESiA) trial. Am Heart J 2017;189:137-45. doi: 10.1016/j.ahj.2017.04.008

37. Kirchhof P, Blank BF, Calvert M, Camm AJ, Chlouverakis G, Diener HC, Goette A, Huening A, Lip GYH, Simantirakis E, Vardas P. Probing oral anticoagulation in patients with atrial high rate episodes: Rationale and design of the Non-vitamin $\mathrm{K}$ antagonist Oral anticoagulants in patients with Atrial High rate episodes (NOAH-AFNET 6) trial. Am Heart J 2017;190:12-8. doi: 10.1016/j.ahj.2017.04.015 